\title{
Entre a espada de Caxias e a balança de Themis: mudanças institucionais, guerre révolutionnaire e Justiça Militar na ditadura de 1964
}

\author{
Erika Kubik da Costa Pinto
}

Resumo: O objetivo deste artigo é mostrar a influência francesa da guerre révolutionnaire nas mudanças institucionais que deram à Justiça Militar o protagonismo sobre a repressão judicial da oposição política no Brasil durante a ditadura que se inicia em 1964. Essas mudanças vinculam-se às estratégias francesas de "parada" e "resposta", que orientam a criação de um novo arcabouço jurídico para contenção da guerrilha, sob direção política das Forças Armadas.

Palavras chave: Justiça Militar, Guerra Revolucionária, Ditadura

\begin{abstract}
The aim of this article is to show how the French theory of guerre révolutionnaire influenced certain institutional changes within the Brazilian Military Judiciary during the military dictatorship that began in 1964. By way of these changes, the Military Justice system took on a leading role in the judicial repression of the political opposition in Brazil. This institutional transformation derived from the French strategies of "restraint" and "response", which guided the creation of a new legal framework for guerrilla containment under the political direction of the Armed Forces.
\end{abstract}

Key words: Military Justice, Revolutionary War, Dictatorship 
Pinto, Erika Kubik da Costa. Entre a espada de Caxias e a balança de Themis: mudanças institucionais, guerre révolutionnaire e Justiça Militar na ditadura de 1964.

É comum a ideia de que os anos que seguiram o golpe de 1964 tenham sido marcados por uma espécie de "esquizofrenia legislativa", uma ânsia desordenada dos militares em institucionalizar a ditadura nos seus diversos níveis. Este trabalho, no entanto, toma como pressuposto que as diversas mudanças institucionais levadas a cabo pelos militares durante a ditadura de 1964 nunca foram desordenadas ou "esquizofrênicas", ao contrário. Documentos da Escola Superior de Guerra (ESG), datados do final dos anos de 1950, apresentavam um novo e necessário desenho de Estado orientado pela matriz francesa do pensamento da guerre révolutionnaire ${ }^{1}$.

O objetivo deste artigo é mostrar como a teoria da Guerra Revolucionária Francesa, assimilada pela ESG a partir de 1959, dialoga com a trajetória de dependência da Justiça Militar, com certa tendência dos militares brasileiros em intervir diretamente na política, e resulta na determinação da Justiça Militar como locus de processo e julgamento da repressão política após o AI $\mathrm{n}^{\mathrm{o}}$ 2, dando conta de objetivos como a contenção da mobilização política e a repressão dos movimentos de oposição.

\section{Marco teórico}

Os militares que chegaram ao poder com o golpe de 1964 não encontraram uma "tabula rasa institucional". Na realidade, herdaram da institucionalidade de 1946 um conjunto de instituições democráticas que definiam as regras do jogo de um governo republicano. O Ato Institucional de nove de abril de 1964 (AI-1) rompeu essa ordem democrática herdada e formalizou uma espécie de hibridismo institucional que caracterizou a ditadura civil militar. Hibridismo este baseado na manutenção de instituições liberais-conservadoras, com mudanças institucionais de viés autoritário orientadas para legitimar muitos dos objetivos estatais de permanência e perpetuação da ditadura no poder ${ }^{2}$.

As políticas institucionais de permanência e estabilidade destes regimes são definidas a partir dos seus contextos estatais. ${ }^{3}$ Assim, a existência e o funcionamento de instituições liberais nas

\footnotetext{
${ }^{1} \mathrm{O}$ principal documento que mostra uma reorientação doutrinária e a preocupação dos militares com um novo desenho de Estado capaz de frear o desenvolvimento comunista é "Introdução ao Estudo da Guerra Revolucionária. Palestra do coronel Augusto Fragoso. Escola Superior de Guerra, C 85-59”, de 1959. Ao longo do artigo, serão apresentadas as mudanças legislativas propostas pela ESG e, principalmente, as que tiveram impacto direto nas mudanças institucionais da Justiça Militar.

${ }^{2}$ Autores apontam para diferenças significativas entre os regimes autoritários a partir de marcos teóricos distintos. Ver, por exemplo, Anthony Pereira (2005) que analisa a diversidade da repressão judicial entre os regimes autoritários latino-americanos a partir das relações judiciais e militares.

${ }^{3}$ Neste artigo, tomamos a importância do contexto institucional para a permeabilidade de ideias e atores nas mudanças institucionais como uma das chaves explicativas para as diferenças entre os padrões diversos da repressão judicial dos regimes autoritários latinoamericanos.
} 
Pinto, Erika Kubik da Costa. Entre a espada de Caxias e a balança de Themis: mudanças institucionais, guerre révolutionnaire e Justiça Militar na ditadura de 1964.

ditaduras contemporâneas extrapolam o argumento da "fachada democrática", muito usado nas análises de instituições de perfil liberal em contextos ditatoriais. ${ }^{4}$

A ditadura brasileira não seria capaz de se manter apenas pela força por mais de vinte anos. Neste período, os sucessivos governos militares tiveram que considerar os constrangimentos e as oportunidades das instituições herdadas, bem como o controle sobre os movimentos sociais, disputas políticas e os espaços institucionais, antes franqueados à oposição. Isso significa que as escolhas institucionais foram definidas a partir dessa complexa relação dos atores na adequação dos interesses e ideias à distribuição do poder.

Algumas ideias foram fundamentais para determinar que a Justiça Militar seria a instituição responsável pela legitimidade da repressão política da ditadura militar no processo e julgamento da oposição civil. ${ }^{5}$ Entre essas ideias deve-se enfatizar a tradição histórica da Justiça Militar, o papel das Forças Armadas na sociedade brasileira e a redefinição do papel brasileiro na geopolítica da Guerra Fria, orientada a partir da teoria da guerre révolutionnaire.

Este conjunto de ideias impactou na produção intelectual da Escola Superior de Guerra (ESG) anos antes do golpe de 64, influenciando a formação das preferências dos oficiais que seriam protagonistas do governo militar. A Doutrina de Segurança Nacional, como é conhecido o conjunto desta produção, compôs o ethos militar e legitimou o papel interventor das Forças Armadas no cenário político com a elaboração de um projeto de nação que dependia de estratégias de controle e contenção.

No campo externo à instituição militar, a confiança dada por setores da sociedade e do sistema partidário às Forças Armadas como solucionadoras da crise política, impulsionaram e legitimaram o seu papel interventor. $\mathrm{Na}$ interpretação de Edmundo Campos Coelho (1976), o período entre 1946 e 1964 é marcado pela política laudatória. Havia a percepção, dentro da sociedade brasileira, de que as Forças Armadas deveriam atuar em espaços designados a outros atores políticos. Nesse contexto, o grupo que atuava na ESG, e que ficou conhecido como Sorbonne Militar, teve um importante papel na definição de um projeto de segurança nacional e desenvolvimento, no qual foi conferido protagonismo aos militares e ao setor empresarial, em detrimento do sistema de partidos e da ação dos movimentos sociais vigentes desde 1946. Em torno desse projeto, a ESG

\footnotetext{
${ }^{4}$ Maria Dalva Gil Kinzo em Oposição e Autoritarismo: a Gênese do MDB (1988), por exemplo, é uma das pesquisadoras que recorrem ao argumento da "fachada democrática" para explicar a manutenção de instituições de oposição durante a ditadura brasileira.

${ }^{5}$ Em Political Injustice: Authoritarianism and the rule of law in Brazil, Chile and Argentina (2005), Anthony Pereira propõe que a maior judicialização da repressão teria como resultado uma menor incidência de mortos e desaparecidos e um elevado número de processos judiciais de crime político em relação aos demais países analisados na pesquisa. A proporção estabelecida, considerando o número de processos judiciais de crime político em relação ao número de mortos e desaparecidos, foi de 23/1 no Brasil (1964/1979), 1,5/1 no Chile (1973/1979) e 1/71 na Argentina (1976/1983).
} 
produziu e enraizou uma nova elite burocrática, atuante também no Judiciário e na Justiça Militar, e que foi a base para composição da parcela civil dos juízes do Superior Tribunal Militar (STM). ${ }^{6}$

No aspecto interno, a inserção dos militares na política e seu intervencionismo surgem muito antes de 1964. Dreifuss e Dulci (2008:136) apontam que houve uma transformação paulatina dos aspectos políticos, ideológicos, institucionais e organizacionais em relação às Forças Armadas. Em relação ao intervencionismo militar, juntam-se à nova doutrina da ESG outros elementos: as ações da União Democrática Nacional, que via nos militares uma solução à crise política; a ideia do poder moderador, e a relativização dos limites da Constituição, por exemplo. O poder moderador, cuja definição tem nas obras de Alfred Stepan e Fernando Pedreira fontes determinantes, compara o papel dos militares com o do imperador na monarquia brasileira: mediar conflitos e impor novas ordens. José Murillo de Carvalho (2005), em um seminal trabalho sobre as Forças Armadas brasileiras, aponta outro fator a levarmos em consideração: a ideologia do soldado-corporação. Oriunda das primeiras décadas do século XX, essa ideologia defende que as Forças Armadas devem atuar na política como um bloco, afastando a ideia de intervenção pessoal do militar nessa arena.

Esse conjunto de ideias repercutiu na judicialização da repressão política. Nesse sentido, a Justiça Militar se enquadrava confortavelmente nos objetivos estratégicos de contenção da oposição e perpetuação no poder, aliados à confiabilidade institucional herdada da visão laudatória. Haveria na atuação da Justiça Militar uma legitimidade potencializada por integrar o poder judiciário, além de herdar uma confiança das instituições militares pautada no escabinato e no seu histórico uso político contra a oposição.

\section{A Justiça Militar: um tribunal inquinado de exceção}

A Justiça Militar brasileira foi criada por Dom João VI, com a vinda da família real para o Brasil, por meio do Alvará de 1ํo de abril de 1808. O Conselho Supremo Militar e de Justiça, com sede no Rio de Janeiro, foi o primeiro tribunal superior que cumulou competências administrativas e jurisdicionais, julgando em última instância aqueles que estivessem submetidos à sua jurisdição. Este equivalente histórico do Superior Tribunal Militar era composto por quinze conselheiros, sendo doze deles representantes da Guerra, do Almirantado e Vogais, e três deles, civis - um ministro relator e dois adjuntos. Todos eram nomeados livremente pelo monarca. A composição mista do órgão judiciário por juízes leigos e militares de carreira, atuando de forma conjunta no exercício de sua competência jurisdicional, tem o nome de escabinato no Brasil, e funciona assim até hoje. (Souza e Silva, 2016: 366).

\footnotetext{
${ }^{6}$ No ANEXO I deste artigo estão listados os nomes dos ministros nomeados para o STM e a origem de sua formação. Entre os anos de 1965 e 1969, os presidentes militares nomearam 15 ministros para o STM, a maioria deles ligados à Escola Superior de Guerra, dentre eles o ex-presidente Ernesto Geisel, nomeado em 1965.
} 
Pinto, Erika Kubik da Costa. Entre a espada de Caxias e a balança de Themis: mudanças institucionais, guerre révolutionnaire e Justiça Militar na ditadura de 1964.

A falta de um Código Penal Militar deixou um vácuo institucional em relação à competência das Juntas Militares e isso permitiu que esse espaço fosse ocupado de forma arbitrária, julgando civis e movimentos sociais - como a Confederação do Equador ${ }^{7}$ - e protegendo oficiais da justiça comum.

Esta característica prevaleceu nos primeiros anos da República. Exemplo disso, foi o Decreto no 85-A de Deodoro da Fonseca, com a finalidade de reprimir manifestações de natureza política favoráveis à Monarquia. Souza e Silva (2016: 371) mostram que os objetivos deste decreto desenham uma herança histórica que acompanhará a Justiça Militar durante o período republicano.

Em cinco de novembro de 1890, Deodoro da Fonseca editou, por meio do Decreto no 949, o primeiro Código Penal Militar brasileiro que, inspirado por princípios liberais, estabelecia garantias processuais, condutas criminosas e suas respectivas penas. A competência da Justiça Militar foi mantida para processar e julgar civis por atos atentatórios ao governo, especialmente nos crimes de espionagem e aliciação.

A continuidade do julgamento de civis na Justiça Militar é notável nos momentos de crise política. A Revolução de 1930, nesse aspecto, não difere dos primeiros anos da República ou daquilo que veremos em 1964, como salientado por Souza e Silva (2016: 378).

Após a promulgação da Constituição de 1934, Getúlio Vargas propõe mudanças institucionais no sentido do fechamento dos canais de participação e oposição política. Sob efeito das sublevações comunistas que marcaram a Intentona, a primeira Lei de Segurança Nacional do Estado Novo foi publicada em 1935 e, por meio do Decreto no 244 de 1936, Getúlio Vargas criou o Tribunal de Segurança Nacional (TSN) para reprimir judicialmente os movimentos comunistas e a oposição política durante o Estado Novo.

O TSN foi instituído a partir de uma mudança estrutural e de competência da Justiça Militar. As sentenças do Tribunal eram definidas por maioria dos votos, cabendo recurso ao STM. Interessante perceber que o TSN integrou a primeira instância da Justiça Militar cumprindo uma finalidade política. Reynaldo Pompeu de Campos (1981: 21) propõe alguma equivalência entre o TSN com o Tribunal do Povo Alemão do III Reich ${ }^{8}$ o Tribunal de Defesa do Estado Fascista Italiano.

\footnotetext{
${ }^{7}$ A Confederação do Equador foi um movimento de natureza separatista e republicana ocorrido em Pernambuco em 1824 após a dissolução da Assembleia Nacional Constituinte de 1823 por D. Pedro I. Líderes do movimento, como Frei Caneca, foram condenados à forca pela Justiça Militar.

${ }^{8}$ O Tribunal do Povo Alemão, criado em 1933 para processar e julgar os considerados "inimigos do Reich", pode ser considerado um dos tribunais mais arbitrários da Alemanha nazista, por desconsiderar qualquer princípio ou garantia de direito. Era composto por juízes civis e membros do Partido Nazista. Ver: SALGADO, Injustiça na justiça do nazismo - Relatos de sobreviventes da rosa branca. Tradução em Revista: São Paulo, no 21, 2006. O Tribunal de Defesa do Estado Fascista italiano, criado em 1925 por Mussolini, era composto por membros das Milícias de Segurança Nacional e competente para o processo e julgamento de crimes políticos.
} 
Pinto, Erika Kubik da Costa. Entre a espada de Caxias e a balança de Themis: mudanças institucionais, guerre révolutionnaire e Justiça Militar na ditadura de 1964.

Para o autor, o Tribunal de Segurança Nacional foi criado "inquinado como órgão de exceção", violando a Constituição de 1934, que determinava a impossibilidade de foro de exceção no país.

Em 1965, por meio do Ato Institucional no22, é novamente somada à competência estrita da Justiça Militar a competência para processar e julgar civis acusados de crimes contra a segurança nacional, crimes contra a probidade administrativa e crimes contra a economia popular. Nos anos que se seguiram, a Justiça Militar processou e julgou milhares de civis e militares acusados de crimes contra a segurança nacional.

Percebe-se, portanto, que no Brasil a tendência à excepcionalidade acompanhou a trajetória do tribunal mesmo quando sua competência foi fixada constitucionalmente, como ocorreu nas Constituições de 1934 e 1946. Nesse sentido, a judicialização da repressão, como estratégia de contenção da oposição durante a ditadura de 1964, foi resultado de uma complexa combinação de fatores históricos e estratégicos que alinhou interesses e ideias dos grupos que dominaram o processo político naquele período, cujo protagonismo se deve, num primeiro momento, à ESG.

\section{Escola Superior de Guerra e Doutrina de Segurança Nacional}

A Escola Superior de Guerra (ESG) foi criada por meio da Lei no 785, de 20 de agosto de 1949. Sua criação teve por objetivo "desenvolver e consolidar os conhecimentos necessários para o exercício das funções de direção e para o planejamento da segurança nacional" (artigo 1º). Sua composição era híbrida, civil e militar, tanto no que se refere aos servidores quanto aqueles que poderiam participar de seus cursos.

A criação da ESG, num primeiro momento, associou-se à experiência do Brasil na Segunda Guerra Mundial, sob comando norte-americano. ${ }^{9}$ Para o general Oswaldo Muniz Oliva, “necessário se tornava implantar, na vida pública, mentalidade moderna, orientada para o planejamento e o trabalho, com técnica, produtividade e pertinácia" (1989: 11). A Escola teve como referência o National War College americano, criado dois anos antes com a função de elaborar estratégias militares de defesa e aperfeiçoamento profissional das Forças Armadas, assim como o Imperial War College, do Reino Unido, criado em 1927 e o Institut des Hautes Études Militaires, da França, criado em 1936.

Para Eduardo Svartman (2006: 120), a ESG, ao importar o modelo norte-americano de Escola, acabou por inovar a metodologia de ensino militar. O que significa afirmar que, após a difusão da metodologia militar norte-americana, começam a existir condições para a reflexão sobre uma "doutrina militar brasileira", possibilitada pela estruturação dos cursos divididos em palestras,

\footnotetext{
${ }^{9}$ Para o General Oswaldo Muniz de Oliveira a criação da ESG estava associada a dois fatores distintos resultantes das experiências vividas pela FEB na Itália. A primeira delas relacionadas a experiência da humilhação pela invasão do território por tropas inimigas e a segunda relacionada à "eficiência, precisão e poderio apresentados pela máquina de guerra americana". Para esse relato vale a leitura do artigo A Escola Superior de Guerra na Revista da Escola Superior de Guerra, n 12, 1989.
} 
Pinto, Erika Kubik da Costa. Entre a espada de Caxias e a balança de Themis: mudanças institucionais, guerre révolutionnaire e Justiça Militar na ditadura de 1964.

discussões e trabalhos em grupo associados ao protagonismo militar no planejamento da segurança nacional.

O argumento de Svartman vai ao encontro do pensamento de Martins Filho quanto ao processo histórico de construção da mentalidade militar brasileira. Martins Filho (2008: 39) rebate o argumento corrente na literatura sobre relações civis-militares de que a doutrina norte-americana teria sido transmitida praticamente sem modificações para as escolas de segurança nacional da América Latina. Para o autor, relegar a um plano secundário os processos internos de construção da mentalidade militar na América Latina significaria reduzir o papel dos setores militares que apoiaram os golpes à "simples marionetes ideológicas, sem história política ou capacidade de gerar seus próprios mitos, doutrinas ou ideologias" (2009: 181).

A ESG teve um papel fundamental na construção do pensamento militar e da Doutrina de Segurança Nacional brasileira. Para compreender esse processo de construção, devemos considerar o contexto geopolítico do pós Segunda Guerra, com a criação do Tratado Interamericano de Assistência Recíproca (TIAR).

Esse tratado foi assinado no Rio de Janeiro em 1947, e contou com a adesão de dezoito dos países americanos. ${ }^{10}$ Em linhas gerais, ele inseria nas relações entre seus signatários a ideia de uma "assistência recíproca" em caso de agressão interna ou externa de qualquer um deles.

Esse Tratado de Assistência Recíproca era parte da "política de contenção" norte-americana, uma estratégia para barrar a expansão do domínio soviético por meio de acordos de cooperação militar e econômica, ao mesmo tempo em que consolidava o protagonismo e a hegemonia estadunidense nas relações internacionais. ${ }^{11}$ Enquanto o TIAR teria sido um "canal de articulação político-militar da hegemonia norte-americana no continente", ${ }^{12}$ o delineamento efetivo dessa hegemonia na dicotomia da Guerra Fria ocorre com a criação da Organização do Tratado do Atlântico Norte (OTAN) no ano seguinte.

Nesse contexto internacional de "contenção ao comunismo" e de "proteção hemisférica", o papel de potência dos EUA estava definido. No entanto, faltava nessas políticas a definição do papel dos países periféricos. Para o Brasil, por exemplo, era importante considerar suas potencialidades e

\footnotetext{
${ }^{10}$ O TIAR - Tratado Interamericano de Assistência Recíproca foi adotado no Rio de Janeiro em setembro de 1947 e representava a formalização da Conferência Interamericana sobre os problemas de Guerra e Paz. Naquele momento assinaram o TIAR: Argentina, Brasil, Chile, Colômbia, Costa Rica, República Dominicana, El Salvador, Guatemala, Haiti, Honduras, Panamá, Paraguai, Peru, Estados Unidos, Uruguai, Bolívia, México e Venezuela.

11 O governo do presidente Eurico Gaspar Dutra se estabeleceu sobre parâmetros anticomunistas resultantes da "política de contenção" americana. Neste sentido, interessante o trabalho de: MANTOVANI, Thais. A doutrina de contenção e a repressão social durante o governo Dutra. ANPUH, João Pessoa, 2003.

12 Disponível em CPDOC/FGV verbete Tratado Internacional de Assistência Recíproca (TIAR), http://www.fgv.br/cpdoc/acervo/dicionarios/verbete-tematico/tratado-interamericano-de-assistencia-reciproca-tiar
} 
Pinto, Erika Kubik da Costa. Entre a espada de Caxias e a balança de Themis: mudanças institucionais, guerre révolutionnaire e Justiça Militar na ditadura de 1964.

protagonismo regional nessa nova dinâmica da Guerra Fria. Papel este que foi construído a partir de algumas premissas.

Uma delas foi o anticomunismo, utilizado habilmente por Getúlio Vargas para criar uma identidade própria à instituição militar que, no início da década de trinta, enfrentava uma série de rebeliões. A narrativa das revoltas de 1935, que ficaram conhecidas como Intentona, possibilitou a criação de novos rituais e de um mito de origem que associava o comunismo como o instigador da desordem e o traidor dos valores mais caros aos militares: camaradagem, hierarquia e disciplina (Santos, 2018: 40). A influência do anticomunismo acompanha os militares brasileiros desde então, e permanece ao longo da Segunda Guerra Mundial. Com a aproximação entre Estados Unidos e Brasil no esforço de guerra e no envio de militares para compor a tropa aliada, essa identidade ganha novos contornos para legitimação.

A produção de uma Doutrina brasileira tem início com a conferência do general Oswaldo Cordeiro de Farias, em 1952, quando propõe o desenvolvimento de objetivos nacionais e de uma política nacional estratégica a partir do alto escalão governamental ${ }^{13}$. Nesse primeiro momento de desenvolvimento da Doutrina de Segurança Nacional, dois conceitos eram considerados fundamentais: Segurança e Desenvolvimento. A primeira conceituação de Segurança Nacional foi conferida à Idálio Sardenberg, em 1953. Nela, a segurança se ligava à ideia de defesa, enquanto o desenvolvimento se relacionava com a exploração do potencial nacional. Era a ideia do Brasil grande, preocupação que acompanhou os militares brasileiros que participaram da Segunda Guerra Mundial.

O conceito de Segurança Nacional vai se tornando predominantemente militar e voltado para dentro do território, a partir da percepção de que uma provável guerra entre as duas superpotências seria nuclear. Nesse sentido, caberia aos EUA serem, no plano externo, os principais defensores de uma agressão vinda dos soviéticos. Ao Brasil e demais países caberia a defesa interna decorrente da ameaça de um inimigo ligado ao comunismo internacional.

Ao conceito de Segurança, antes compreendido como a segurança externa da nação, se agrega a ideia de segurança interna como continuidade da política internacional. Para dar conta de um inimigo interno, identificado a partir do movimento do comunismo internacional, estratégias específicas deveriam ser utilizadas. A noção da segurança muda no sentido mesmo do redimensionamento do conceito de guerra na geopolítica - de guerra clássica para guerra nuclear e Guerra Revolucionária.

\footnotetext{
${ }^{13}$ Antonio de Arruda, conselheiro da ESG, num artigo que trata da formulação da Doutrina da ESG, mostra que o documento Conceito Estratégico Nacional, C-010-52, do general Cordeiro de Farias, foi o primeiro em formular uma Política de Segurança Nacional. Arruda, Antonio. Doutrina da ESG: principais alterações ocorridas nas últimas quatro décadas. Revista da Escola Superior de Guerra: Rio de Janeiro, 1989.
} 
Pinto, Erika Kubik da Costa. Entre a espada de Caxias e a balança de Themis: mudanças institucionais, guerre révolutionnaire e Justiça Militar na ditadura de 1964.

Como resultado, a doutrina brasileira se caracterizava por ser defensiva à ameaça externa representada pelo comunismo internacional e, ao mesmo tempo, associativa em termos de segurança hemisférica. Considerando, ainda, que o comunismo internacional fundamentaria sua ação a partir das tensões e conflitos internos de uma população em relação ao seu governo, os militares brasileiros passaram a integrar o desenvolvimento econômico e social às discussões sobre segurança interna.

Muitas das ideias que tomaram corpo na ESG no final dos anos 1950 e começo dos 1960 tiveram consequências normativas importantes depois de $1964 .{ }^{14}$ Interessante que propostas para mudanças institucionais incluídas na palestra do futuro ministro general do STM Augusto Fragoso, em 1959, estavam vinculadas à regulação do papel das forças armadas e do poder civil frente ao novo cenário apresentado pela Guerra Revolucionária (ESG, C-85-59). Para Emilio Dellasoppa (1998: 237), essa nova concepção dos papéis político e social definidos para as Forças Armadas qualificava a instituição como um agente de modernização, mascarando o cerne intervencionista da doutrina da Guerra Revolucionária.

\section{A influência francesa na Doutrina de Segurança Nacional brasileira}

Para Héctor Saint-Pierre (2000: 68) “a guerra revolucionária é uma guerra civil, no qual o fundamento último do conflito, sua caracterização política, é a agudização bélica da luta de classes". O fenômeno da Guerra Revolucionária não é novo na história. John Shy e Thomas Collier (2003: 467) mostram que a eclosão de movimentos de caráter revolucionário foi frequente, o novo ingrediente que surgiu a partir da segunda metade do século XX foi a construção de ferramentas teóricas capazes de analisar o fenômeno intimamente ligado a questões político-ideológicas.

Estas ferramentas de análise surgiram associadas a dois fatores internacionais - o imperialismo e o comunismo - catalisados após a vitória dos comunistas chineses em 1949, e as guerras de libertação na Ásia e na África (Shy e Collier, 2003: 499). Os escritos de Mao Tsé-Tung deram conta de uma nova maneira de conduzir um conflito marcado pela assimetria de forças, baseando-se no tempo prolongado da ação, no espaço e no apoio e mobilização da população. Estes escritos inspiraram a ação revolucionária; por outro lado, a contra-ofensiva viria dos militares franceses.

Segundo os autores (2003: 517), a expressão guerre révolutionnaire: “descrevia um diagnóstico e uma receita para aquilo que um grupo de militares franceses de carreira viam como a principal enfermidade do mundo moderno - o fracasso ocidental em enfrentar o desafio da ateísta subversão

\footnotetext{
${ }^{14}$ A criação do Serviço Nacional de Informações e a estruturação do Curso de Informações, que existiu entre 1965 e 1972 , foram propostas dos militares da Escola. Outro exemplo foi a limitação dos partidos políticos e a fidelidade partidária discutidas em 1959 no documento C 85-59, incorporadas à Constituição de 1964 por meio do Ato Institucional nº2.
}

S RASILIANA: Journal for Brazilian Studies. Vol. 10, No. 2, 2021. ISSN 224.5-4373. 
Pinto, Erika Kubik da Costa. Entre a espada de Caxias e a balança de Themis: mudanças institucionais, guerre révolutionnaire e Justiça Militar na ditadura de 1964.

comunista". Neste sentido, os EUA e seus aliados estariam hipnotizados com a possibilidade de uma guerra nuclear, sem perceber o avanço do comunismo no sul: China, Indochina, Egito e Argélia ${ }^{15}$

Influenciados pelos franceses, a ESG inicia um processo de redefinição doutrinária ainda em 1959. O documento C-85-59 “Introdução ao estudo da Guerra Revolucionária” representou um marco divisório nos debates militares sobre as formas de guerra e o inimigo interno a ser combatido, fundamentado numa conceituação básica sobre a teoria da Guerra Revolucionária.

O então coronel Augusto Fragoso orientou a produção desse documento, mostrando que só havia a bibliografia francesa sobre a Guerra Revolucionária ${ }^{16}$. Fragoso chegou ao posto de general e, ao fim da carreira, foi nomeado ministro do STM, fato que também ocorreria com outros colegas que cursaram a ESG e indica uma circulação de ideias e valores nos componentes militar e civil daquela Corte.

Em um âmbito regional, Fragoso é contemporâneo de outras iniciativas no cone sul, o que mostra o enraizamento da influência francesa ${ }^{17}$. Segundo Martins Filho, as primeiras referências ao pensamento militar francês da guerre révolutionnaire na região datam dos anos 1950. Em 1956, o coronel Carlos Rosas, ao assumir a direção da Escuela Superior de Guerra em Buenos Aires, passa a redefinir a doutrina argentina com base na experiência narrada pelos veteranos das guerras coloniais da Indochina e da Argélia. (Dellasoppa, 1998: 238 e Martins Filho, 2008: 179). Em 1958, os trabalhos publicados pelo coronel francês de Naurois na revista da Escola Superior de Guerra argentina forneceram as bases teóricas para o desenvolvimento de uma doutrina específica, a partir de um comando político-militar único, com ênfase nas funções de comunicação e informação.

Neste aspecto existiu, nos anos 1960, uma espécie de cultura política transnacional do risco revolucionário. De acordo com Chirio (2012: 23), apesar da doutrina francesa se basear num contexto colonial específico - Indochina e Argélia - a desconfiança com relação à classe política civil e uma espécie de paternalismo e desprezo pela população, que seria alvo fácil da internacionalização do comunismo, levaram os militares brasileiros a conceber um sistema político e social específico.

\footnotetext{
${ }^{15}$ O primeiro documento americano a tratar da Guerra Revolucionária foi o NSAM 124 de 1961, dois anos após a palestra de Augusto Fragoso na ESG.

${ }_{16}$ Augusto Fragoso indica no documento de 1959 que a Military Review norte-americana, entre janeiro de 1958 e fevereiro de 1959 , não trouxe qualquer artigo ou tópico sobre Guerra Revolucionária, guerra insurrecional ou guerra subversiva. As fontes usadas pelo general Augusto Fragoso naquela ocasião eram todas francesas. Como mostra Martins Filho (2008: 184) estariam entre elas o documento Contribuition a une étude sur la guerre révolutionnaire, publicado pela Escola Superior de Guerra de Paris em 1955, o livro do coronel Gabriel Bonnet, Les Guerres Révolutionnaires e Insurrectionelles, de 1958, La Troisiéme Guerre Mondiale de Pierre Debray de 1958 e La Guerre Revolutionnaire de Claude Delmas de 1959.

17 Para compreender o movimento da internacionalização das elites militares francesas para a América Latina e a influência do pensamento militar francês sobre os exércitos latino-americanos ver o documentário Escadrons de la mort: L'école Française de MarieMonique Robin e o livro Je n'ai pas tout dit: ultimes révélations au service de la France (2008), que traz as memórias do General Paul Aussaresses, que comandou os serviços especiais franceses na Argélia e foi adido militar francês no Brasil entre 1973 e 1976, não por acaso o período mais violento da repressão brasileira.
} 
Pinto, Erika Kubik da Costa. Entre a espada de Caxias e a balança de Themis: mudanças institucionais, guerre révolutionnaire e Justiça Militar na ditadura de 1964.

Numa entrevista concedida a Maria Celina D’Araujo, o general Otavio Costa ilustra o contexto da entrada do pensamento francês no Brasil (apud Martins Filho, 2008: 41):

Nesse momento, estávamos profissionalmente perplexos, sem saber que direção tomar. Então começamos a tomar conhecimento de novas experiências. Nessa ocasião a literatura militar francesa começa a ser formulada e surge um novo tipo de guerra. Era a guerra infinitamente pequena, a guerra insurrecional, a Guerra Revolucionária. Isso entrou pelo canal da nossa Escola Superior de Guerra, e foi ela que lançou as ideias sobre a guerra insurrecional e revolucionária e passamos a nelas identificar o quadro da nossa própria guerra possível. Para nós ainda não havia guerra nuclear, a guerra convencional já estava ultrapassada. Mas havia uma guerra que nos parecia estar aqui dentro. Isso tudo contribuiu para a formulação da nossa própria doutrina da Guerra Revolucionária, que resultou no movimento militar de 64 .

Na década de 60, a Guerra Revolucionária incorporada à Doutrina de Segurança Nacional brasileira passa a ser compreendida como "um processo permanente de subversão, conduzido por uma adestrada minoria comunista, infiltrada nos principais setores da estrutura administrativa e social dos países democráticos, visando a sua desagregação". ${ }^{18}$ Esta interpretação é importante para compreender as mudanças institucionais de ordem macro após o golpe, principalmente no que se refere às mudanças institucionais orientadas para o processo e julgamento da oposição política.

O modelo francês da guerre révolutionnaire era desenhado em cinco etapas, como demonstra o esquema disposto no documento da ESG 85-59. As três primeiras eram compreendidas como preparatórias das ações revolucionárias. As duas seguintes eram as etapas de execução das ações, com o estabelecimento de zonas liberadas, formação de um governo provisório e de um exército regular revolucionário.

Os militares brasileiros adaptaram o modelo francês ao contexto nacional reduzindo-o a duas estratégias de ação: parada e resposta. A estratégia de parada visava conter a oposição política por meio de mudanças institucionais sobre os diversos setores - político, militar, educacional e dos trabalhadores. Daí decorreram mudanças institucionais que marcaram profundamente a ditadura brasileira, como uma nova Lei de Diretrizes e Bases, o bipartidarismo e a restrição da ação dos sindicatos e da imprensa livre, por exemplo.

Ainda em 1959, o coronel Fragoso enfatizou sua preocupação com as garantias processuais e o acesso à Justiça. Na sua visão, "um ruidoso habeas corpus, habilmente explorado, não só irrita e

\footnotetext{
${ }^{18}$ Em 1969, a Escola Superior de Guerra dá homogeneidade ao conceito de guerra clássica como “o litígio entre nações ou grupos de nações", enquanto a Guerra Revolucionária como o conflito que "visa à conquista e manutenção do poder em favor do comunismo internacional por intermédio da população" (ESG, C-20-69). Para o brigadeiro Zamir de Barros Pinto (ESG, 1961), a guerra teria abandonado seu caráter de "ato de força exclusivo das Forças Armadas" para assumir "um caráter predominantemente político, com profundas repercussões socioeconômicas da vida nacional".
} 
Pinto, Erika Kubik da Costa. Entre a espada de Caxias e a balança de Themis: mudanças institucionais, guerre révolutionnaire e Justiça Militar na ditadura de 1964.

desencoraja a população que se vê à mercê da subversão, como desestimula e desmoraliza os agentes da lei". O coronel também enfatiza a necessidade de órgãos e legislação de exceção habilitados a punir a oposição política, incapacitando sua organização. As principais mudanças institucionais que atingiram a Justiça Militar durante a ditadura se concentraram nas tentativas do regime de institucionalizar a repressão política durante o período de parada.

Se as estratégias de parada se caracterizam por medidas normativas e, portanto, de caráter preventivo, são as ações violentas de eliminação do inimigo - tortura institucionalizada, mortes, desaparecimentos e instituição de penas perpétua e de morte para crimes políticos - que definem as estratégias de resposta. É desta fase a unificação dos controles político e militar dos órgãos de segurança e a criação dos DOI CODI.

Neste sentido, enquanto as estratégias de $\operatorname{parada}^{19}$ buscavam um desenho institucional capaz de estancar o avanço das ações revolucionárias ${ }^{20}$, as estratégias de resposta objetivam o uso da violência e da força contra a oposição política.

\section{A influência francesa nas mudanças institucionais na Justiça Militar pós-64}

O limite da atuação da Justiça Militar foi expandido pelo Ato Institucional no 2 (1965) que ampliou sua competência sobre os processos de civis contra a Segurança Nacional, ao alterar a Constituição Federal de 1946.21

A partir deste momento, todos os processos de crimes contra a Segurança Nacional que estavam sendo instruídos pela justiça comum deveriam ser encaminhados para a Justiça Militar. Essa mudança de foro não gerou mudanças significativas imediatas nas condenações no STM. Considerando que o AI-2 foi editado em 27 de outubro de 1965, apenas no ano seguinte começou a ser possível medir o padrão dos julgamentos. ${ }^{22}$

O órgão de primeira instância da Justiça Militar competente para receber os processos remetidos da justiça comum era o Conselho Permanente de Justiça, instalado nas auditorias

\footnotetext{
${ }^{19}$ A primeira fase da Guerra Revolucionária seria a mais perigosa na compreensão dos militares. Haveria um despreparo das instituições brasileiras para enfrentar a ameaça subversiva. A partir de uma leitura particular dos documentos partidários, o general Augusto Fragoso (ESG C-85-59) enquadra o Brasil na primeira etapa do desenvolvimento da Guerra Revolucionária.

${ }^{20}$ Num limite entre as ações de preparação e execução da Guerra Revolucionária, as chamadas técnicas de dissolução do organismo social seriam marcadas por greves, resistência passiva, insuflação das massas por meio de comícios, passeatas e roubos para a obtenção de armamento, veículos e dinheiro. Elas caracterizariam a mudança emblemática nas ações contrarrevolucionárias dos militares, com ações ostensivas por parte das Forças Armadas.

${ }^{21}$ Artigo $108, \S 1^{\circ}$ - Esse foro especial poderá estender-se aos civis, nos casos expressos em lei para repressão de crimes contra a Segurança Nacional ou as instituições militares."

${ }^{22}$ Durante a pesquisa do doutorado, a autora construiu um banco de dados a partir do Projeto Brasil: Nunca Mais. Um levantamento feito na pesquisa demonstra que dos processos políticos de crime contra a Segurança Nacional julgados pelo STM, as absolvições chegaram a 80\% entre os anos de 1966 e 1969.
} 
Pinto, Erika Kubik da Costa. Entre a espada de Caxias e a balança de Themis: mudanças institucionais, guerre révolutionnaire e Justiça Militar na ditadura de 1964.

militares. De composição mista, característica do escabinato, os Conselhos eram formados por um juiz auditor civil e quatro militares que atuavam como juizes militares em rodízios de três meses.

O auditor civil tinha formação em Direito, e teve as garantias inerentes à magistratura vitaliciedade, inamovibilidade e irredutibilidade - suspensas pelo AI-2. Auditores civis poderiam ser afastados por determinação do Conselho de Segurança Nacional caso não atuassem de acordo com os interesses da revolução - interesses esses que foram formulados majoritariamente por oficiais que serviram à ESG.

A cassação de auditores em decorrência dos Atos Institucionais não foi uma regra durante a ditadura, mas existiu. Exemplo dessa exceção foi a cassação dos auditores Antonio de Arruda Marques, Arnaldo Carnasciali Aureo de Souza Almeida, Humberto Augusto da Silva Ramos e Coryntho Brayner dos Santos pelo presidente Costa e Silva, a pedido do Conselho de Segurança Nacional e do Serviço Nacional de Informações, sob a justificativa de "atividades antirevolucionárias desenvolvidas pelos indiciados, através de sucessivos votos, pareceres e deliberações em defesa de elementos havidos e julgados como subversivos" (N8.PRO.CSS.30.3). ${ }^{23}$

O auditor civil Georgenor Acylino de Lima Torres, nomeado ministro do STM em 1976, teve decisões monitoradas desde 1964, ano em que votou sozinho pela absolvição dos réus no conhecido “Caso dos Chineses" (ARJ-ACE 5942/70). Esse caso foi de grande interesse para a ditadura, sendo citado, inclusive em telegrama do embaixador Lincoln Gordon em 04 de abril de 1964: "In connection with arrests, April 4 papers announced arrest of eight Chinese, members of Communist Trade Mission and NCNA. ${ }^{24 " ~ A ~ p a r t i r ~ d e s s e ~ p r o c e s s o, ~ a s ~ d e c i s o ̃ e s ~ d o ~ a u d i t o r ~ c o m e c ̧ a r a m ~ a ~ s e r ~ c a t a l o g a d a s ~ p e l o s ~ o ́ r g a ̃ o s ~}$ de segurança, que advertiam para que ele não compusesse nenhuma lista para eventual nomeação para o STM.

Dalmo de Abreu Dallari, professor de direito e advogado de presos políticos durante a ditadura, numa entrevista para Maria Celina D'Araujo, do CPDOC, ${ }^{25}$ afirmou que a proximidade das auditorias militares com os quartéis teria gerado um maior controle direto do comando militar sobre as decisões: “As Auditorias eram mais duras no momento da imposição das penas, sem dúvida alguma, porque eu acho que havia uma interferência mais direta, mais imediata dos quartéis sobre as Auditorias. O que não acontecia nos Tribunais superiores."

\footnotetext{
${ }^{23} \mathrm{O}$ processo de cassação dos auditores está disponível no banco de dados do Arquivo Nacional no fundo BR DFANBSB, disponível em: http://imagem.sian.an.gov.br/acervo/derivadas/br dfanbsb n8/0/pro/css/0150/br dfanbsb n8 0 pro css 0150 d0001de0001.pdf acessado em 18 de novembro de 2018.

${ }^{24} \mathrm{O}$ telegrama do embaixador faz parte do dossiê do auditor Georgenor, disponível no Banco de Dados do Arquivo Nacional sob a referência ARJ-ACE 5942/70.

${ }^{25}$ Entrevista concedida para Maria Celina D’Araujo em 21/11/2005 no projeto de pesquisa "200 anos de Justiça Militar”
} 
Pinto, Erika Kubik da Costa. Entre a espada de Caxias e a balança de Themis: mudanças institucionais, guerre révolutionnaire e Justiça Militar na ditadura de 1964.

O AI-2 trouxe uma mudança crucial no desenho institucional do STM: o aumento de onze para quinze ministros componentes da Corte. ${ }^{26}$ Esse aumento não objetivou atender apenas ao maior volume de trabalho no julgamento de civis. Essa mudança tinha natureza política. Os ministros civis, por exemplo, seriam livremente nomeados pelo Presidente da República, sem indicações prévias, definindo assim o perfil do futuro ministro de acordo com afinidades político-ideológicas e negociações anteriores. A livre escolha recaía exatamente sobre os ministros com formação jurídica e melhor capacitados para legitimar legalmente os julgamentos políticos.

A nomeação dos novos ministros do STM para ocupar as quatro vagas abertas não foi imediata. Foram três anos até que as quinze cadeiras estivessem ocupadas. A composição do STM foi toda renovada nos primeiros cinco anos do regime. A maioria dos ministros, fossem eles civis ou militares, tinha formação na Escola Superior de Guerra e estava alinhada ao golpe. Em termos estratégicos, a nova composição permitia um maior controle sobre os julgamentos da Corte.

Em abril de 1964, quando têm início os primeiros Inquéritos Policiais Militares e a punição de indivíduos com base na doutrina da Guerra Revolucionária, os militares não tinham uma legislação de Segurança Nacional própria. Vigorava à época a Lei nº1802/53, produzida pelo Legislativo do governo Getúlio Vargas.

Em 13 de março de 1967 foi editado o decreto-lei 314, a primeira lei de Segurança Nacional da ditadura. Esse decreto-lei, instrumento que diminui a participação do Poder Legislativo, afirmou a competência da Justiça Militar para o processo e julgamento dos crimes nele previstos, de acordo com o que havia sido estabelecido pelo Ato Institucional no 2 . A inserção de um conceito de inimigo interno resultou em ampliar a responsabilidade sobre a Segurança Nacional para todos os cidadãos, inclusive pessoas jurídicas.

A doutrina de Guerra Revolucionária tratava o perigo subversivo como um objeto de permanente atenção, e refletia-se na legislação de Segurança Nacional na forma de qualquer manifestação, pressão ou "antagonismo" ocorridos no âmbito interno do país e contrários ao governo militar. Como um típico direito penal do inimigo, o Decreto-lei 314/67 previa uma tipificação penal aberta e vaga, que colocava o juiz como uma figura central da repressão judicial, que definia se determinada ação era ou não um crime contra a segurança nacional.

O Decreto-Lei 314/67 fez parte das estratégias de parada da ditadura militar, num processo mais amplo de institucionalização do Estado de exceção com base na doutrina de Segurança Nacional. A revista Visão, de 17/02/1967 (apud Martins Filho, 1993: 27), mostra que antes que redigir a nova Lei de Segurança Nacional, o Ministro Carlos Medeiros Silva "ficou à espera dos estudos que

\footnotetext{
26 “O Superior Tribunal Militar compor-se-á de quinze Juízes vitalícios com a denominação de Ministros, nomeados pelo Presidente da República, dos quais quatro escolhidos dentre os Generais efetivos do Exército, três dentre os Oficiais Generais efetivos da Armada, três dentre os Oficiais Generais efetivos da Aeronáutica e cinco civis" (artigo $7^{\circ}$, Ato Institucional n ${ }^{2}$ ).
} 
Pinto, Erika Kubik da Costa. Entre a espada de Caxias e a balança de Themis: mudanças institucionais, guerre révolutionnaire e Justiça Militar na ditadura de 1964.

a respeito foram elaborados em diversos órgãos militares sob a coordenação do EMFA (Estado Maior das Forças Armadas) e de inspiração na doutrina estabelecida na Escola Superior de Guerra". A mesma reportagem de Visão mostra que a nova Lei de Segurança Nacional seria para o governo militar:

O coroamento de sua obra, no terreno da reformulação institucional e política do país, executada sob a égide de Março. (...) Segundo a doutrina aceita pelo governo, a Segurança Nacional assenta em fatores de natureza econômica, política, psicossocial e militar. Proveniente desses quatro compartimentos, tudo o que possa haver caracterizado como fator de perturbação da ordem pública interessará de modo especifico à segurança nacional, em amplitude tal que o redator do projeto terá dificuldade em catalogar, com propriedade, a série de delitos que deixam de ser reprimidos na esfera de outros códigos e leis especificas e passam a ter uma nova definição jurídica.

\section{Considerações Finais}

Os militares que chegaram ao poder em 1964 deram início a um processo de seletividade institucional, objetivando acumulação de poder e perpetuação no poder. Esta seletividade institucional foi operada considerando características herdadas historicamente pelas instituições e escolhas estratégicas do regime para maior controle e contenção da oposição e participação política. O resultado deste processo foi uma maior robustez institucional.

Os militares selecionaram a Justiça Militar como a instituição que legitimaria a repressão à oposição. Esta escolha se relacionou com aspectos históricos da Corte, que foi criada ainda em 1808 com a vinda da família real para o Brasil. Historicamente, o Superior Tribunal Militar, a mais alta corte da Justiça Militar, sofreu investidas do Executivo para dar conta de interesses políticos em situações de crise social e política, passando em vários momentos da história a julgar civis, ampliando assim suas atribuições. Além disso, no âmbito interno das Forças Armadas, a legitimidade também respondia ao ethos militar da hierarquia e da disciplina, ou seja, de respeito às posições de comando. Eram nomeados para o STM militares ocupantes de cargos do topo da carreira, portanto, sem subordinação referente à posicionamentos políticos, o que permitiu o enfrentamento de situações de violações de direitos dos presos e dos pares responsáveis.

Outro destaque no campo das ideias envolvendo a institucionalização da Justiça Militar respondeu à necessidade de controle político militar unificado exigido nas estratégias de parada da Guerra Revolucionária. A partir do Ato Institucional no 2 (AI-2) de outubro de 1965, a competência do foro castrense passou a abranger todo processo e julgamento, inclusive de civis, envolvidos na prática de crimes contra a Segurança Nacional ou às instituições militares. Nesse sentido, o AI-2 trouxe para o interior da Justiça Militar o ideário da Guerra Revolucionária. Pode-se dizer que o Ato Institucional $\mathrm{n}$ ² foi um marco divisório do regime autoritário, que estabeleceu as bases da repressão política, fornecendo ao regime um espaço maior de manobra para sua institucionalização. 
Pinto, Erika Kubik da Costa. Entre a espada de Caxias e a balança de Themis: mudanças institucionais, guerre révolutionnaire e Justiça Militar na ditadura de 1964.

A guerra revolucionária francesa impactou na estruturação de um desenho de Estado que trazia à tona um papel funcional do Brasil na dinâmica internacional estabelecida pela Guerra Fria, privilegiando a contenção do inimigo comunista no âmbito interno. Ou seja, na ameaça da guerra nuclear entre União Soviética e Estados Unidos, o papel do Brasil seria reorientado para a segurança interna, combatendo o foco inimigo que, em tese, se alastrava em ondas nos países periféricos aos blocos americano e soviético. A teoria da guerra revolucionária francesa era elástica o suficiente tanto para dar importância ao Brasil na política de contenção hemisférica americana quanto na definição do inimigo interno.

Daí a grande importância que os militares deram ao Direito e às instituições de forma geral, e ao protagonismo das estratégias de parada, que permitiam uma estrutura legal ao funcionamento da ditadura. Neste sentido, a ditadura de 1964 não parece ter sido o caso de uma esquizofrenia legislativa, mas da necessidade militar de legitimar uma política que fosse capaz, inclusive, de ultrapassar a resistência das instituições ao seu novo papel interventivo na sociedade, tornando o controle centralizado pelo aparato militar.

\section{Referências}

Alves, M.H.M. (1985) Estado e Oposição no Brasil (1964-1984). Petrópolis: Editora Vozes.

Araujo, R. N. \& Marin, R. (2008) Guerra Revolucionária: afinidades eletivas entre oficiais brasileiros e a ideologia francesa (1957 - 1972). Defesa, segurança internacional e forças armadas. Mercado das Letras: São Paulo.

Campos, R. P. (1982) Repressão Judicial no Estado Novo: Direita e esquerda no banco dos réus. Achiamé: São Paulo. Carvalho, J.M. (2005) Forças Armadas e Política no Brasil. Rio de Janeiro: Jorge Zahar Editor.

Chirio, M. (2012). A política nos quartéis. Rio de Janeiro: Zahar Editores.

Coelho, E. C. (2000) Em busca de identidade: o Exército e a política na sociedade brasileira. Rio de Janeiro: Record.

D’Araujo, M. C. (2010) Militares, democracia e desenvolvimento: Brasil e América Latina. Rio de Janeiro: Editora FGV.

D’Araujo, M. C. (2006) Justiça Militar, Segurança Nacional e Tribunais de Exceção. Trabalho apresentado no 30ํㅡㅁ Encontro Nacional da ANPOCS Caxambu.

Dellasoppa, E (1988). Ao inimigo, nem justiça: violência política na Argentina (1943 - 1983). São Paulo: Editora Hucitec.

Dreifuss, R. A. (1981) 1964: A conquista do Estado - Ação Política, Poder e Golpe de Classe. Petrópolis: Editora Vozes.

Dreifuss, R.A. \& Dulci, O.S. (2008) As forças armadas e a política. In SORJ, Bernard \& ALMEIDA, Maria Helena Tavares. orgs. Sociedade política no Brasil pós-61. Rio de Janeiro: Centro Edelstein de Pesquisas Sociais.

Kinzo, M. D. G. (1988) Oposição e Autoritarismo: Gênese e Trajetória do MDB (1966-1979). São Paulo: Vértice.

Lambert-Abdelgawad, E. (2007) Juridictions militaires et tribunaux d'exception en mutation: perspectives compareés et internationales. Éditions des archives contemporaines: Paris, 2007.

B RASILIANA: Journal for Brazilian Studies. Vol. 10, No. 2, 2021. ISSN 2245-4373. 
Pinto, Erika Kubik da Costa. Entre a espada de Caxias e a balança de Themis: mudanças institucionais, guerre révolutionnaire e Justiça Militar na ditadura de 1964.

Leirner, P.C. (1997) Meia volta, volver! Um estudo antropológico sobre a ditadura militar. Rio de Janeiro, Ed.FGV.

Mahoney, J. \& Thelen, K. (2010) Explaining Institutional Change Ambiguity, Agency, and Power. New York: Cambridge University Press, 2010.

Martins Filho, J. R. (1993) O castelismo no poder. Teoria e Pesquisa, ํㅜㄱ, dez.

(2004). A educação dos golpistas: cultura militar, influência francesa e golpe de 1964. Trabalho apresentado no Seminário Internacional Cultures of Dictatorship. Maryland \USA: Universidade de Maryland, setembro.

(2008) A influência doutrinária francesa sobre os militares brasileiros nos anos de 1960. Revista Brasileira de Ciências Sociais, 23 (67): 39, 50, 2008.

(2009). Tortura e ideologia: os militares brasileiros e a doutrina da guerre revolutionnaire (1959 \1974). In Desarquivando a Ditadura: memória e justiça no Brasil. Vol. I. São Paulo: Editora Hucitec.

Paret, P. (2003) Construtores da Estratégia Moderna. Rio de Janeiro, Biblioteca do Exército, tomo 2.

Pereira, A. (2005) Political Injustice: Authoritarianism and the rule of law in Brazil, Chile and Argentina. Pittsburgh: University of Pittsburgh Press.

Pereira, A. (2006). O Papel dos Advogados de Defesa na Justiça Militar Brasileira, 1964-1969. In Martins Filho, João Roberto. O Golpe de 1964 e Regime Militar: Novas Perspectivas: Edufscar. São Paulo,.

Pinto, E.K.C. (2019) Superior Tribunal Militar: Mudança Institucional, Ideias e Atores na Ditadura (1964/1979). Tese de Doutorado em Ciência Política. Universidade Federal Fluminense

Rezende, F.C. (2013) As instituições mudam endogenamente?: Limites e possibilidades da mudança institucional endógena na teoria institucional contemporânea. BIB, São Paulo, n. 76.

Saint-Pierre, H. L. (2000) A política armada: fundamentos da Guerra Revolucionária. Editora Unesp: São Paulo.

Santos. E. H. J. (2018) Outro olhar sobre as Forças Armadas: Os grupos de pressão política formados por militares da reserva. Em Debate: Belo Horizonte, v. 10, no 1, p. 39 - 45, abril 2018.

Schedler, A. (2009). The New Institutionalism in the study of authoritarian regimes. Cidade do México, CIDE.

Silva, A. M. D (2007). Ditadura militar e justiça castrense no Brasil: espaço de legitimação política e de contradições (1964-1985). I Encontro Nacional da Associação Brasileira de Estudos de Defesa. São Carlos.

Shy, J. \& Collier, T. Guerra Revolucionária. In. PARET, P. Construtores da Estratégia Moderna. Rio de Janeiro: Biblioteca do Exército, 2003, tomo 2.

Skidmore, T (2004). Brasil: de Castelo a Tancredo, 1964-1985. $8^{\mathrm{a}}$ ed. Rio de Janeiro: Paz e Terra.

Solomon Jr, P. (2007) Courts and Judges in Authoritarian Regimes. World Politics, (60), Number 1.

Souza, A.B., Silva, A. M. D (2016). A organização da justiça militar no Brasil: Império e República. Revista Estudos Históricos, Rio de Janeiro, v. 29, n. 58, jul.

Stepan, A (1986). Os militares: da abertura à nova república. Editora Paz e Terra, Rio de Janeiro: 1986.

Trinquier, R. (2008) La guerre moderne. Economica: Paris, 2008.

Wanderley, E. K. C. (2009) As Auditorias Militares no aparato repressor do regime ditatorial (1965-1968). Dissertação de mestrado em Ciência Política: Universidade Federal de São Carlos. 
Pinto, Erika Kubik da Costa. Entre a espada de Caxias e a balança de Themis: mudanças institucionais, guerre révolutionnaire e Justiça Militar na ditadura de 1964.

Zaverucha, J; Melo Filho, H. C. (2004). Superior Tribunal Militar: entre o autoritarismo e a democracia. Dados: Rio de Janeiro, v. 47, n. 4, 2004.

\section{Documentos da ESG}

Introdução ao Estudo da Guerra Revolucionária. Palestra do coronel Augusto Fragoso. Escola Superior de Guerra, C 85-59, 1959.

Aspectos da Guerra Contemporânea: A Guerra Revolucionária. Escola Superior de Guerra, C-20-69, 1969. 
Pinto, Erika Kubik da Costa. Entre a espada de Caxias e a balança de Themis: mudanças institucionais, guerre révolutionnaire e Justiça Militar na ditadura de 1964.

\section{Anexo}

\section{Lista dos Ministros do STM nomeados entre os anos de 1965 e 1969}

- General de Exército Pery Constant Bevilacqua - Legalista, primeiro e único ministro a ser alvo do AI-5, foi nomeado em 15 de fevereiro de 1965;

- Tenente Brigadeiro Armando Perdigão - realizou cursos na Escola Superior de Guerra, nomeado em 17 de maio de 1965;

- Almirante de Esquadra Waldemar de Figueiredo Costa - Membro do Corpo Permanente da Escola Superior de Guerra e membro da Comissão elaboradora dos ante-projetos do Código de Processo Penal Militar e de Lei de Organização Judiciária Militar de 1969, nomeado em 11 de agosto de 1965;

- Tenente Brigadeiro Gabriel Grun Moss - foi ministro da Aeronáutica no governo de Jânio Quadros, em 1961 foi representado pelo deputado federal Adauto Lúcio Cardoso por ser contrário à posse do presidente João Goulart, realizou cursos na Escola Superior de Guerra em 1963, participou ativamente do golpe de 64. É nomeado ministro do STM em 10 de setembro de 1965;

- General de Exército Octacílio Terra Ururahy - Comandante do I Exército (interino) em 1964, realizou curso da ESG em 1962, nomeado em 05 de novembro de 1965;

- Tenente Brigadeiro Francisco de Assis Correia de Mello - compôs Comando Supremo da Revolução como comandante da Força Aérea, foi presidente da Comissão Militar Mista Brasil/EUA após a posse do presidente Castelo Branco e nomeado ministro do STM em 08 de novembro de 1965;

- Almirante de Esquadra José Santos Saldanha da Gama - nomeado em 08 de novembro de 1965;

- Alcides Vieira Carneiro - nomeado em 07 de março de 1966;

- General de Exército Ernesto Geisel - foi um dos articuladores do golpe de 64. Nomeado ministro do STM em 20 de março de 1967, passou parte do tempo no STM licenciado de suas funções. Presidiu a Petrobrás entre 1969 e 1973, desligou-se para assumir a presidência da república em 1974;

- Almirante de Esquadra Silvio Monteiro Moutinho -nomeado ministro do STM em 27 de março de 1967;

- Almirante de Esquadra Mario Cavalcanti de Albuquerque - realizou cursos na Escola Superior de Guerra, nomeado em 23 de agosto de 1968;

- Eraldo Gueiros Leite - nomeado em 18 de março de 1968;

- João Mendes da Costa Filho - nomeado em 20 de junho de 1968;

- General de Exército Adalberto Pereira dos Santos - Realizou cursos na Escola Superior de Guerra, comandou tropas anti-governistas em 1964, compôs chapa como vice-presidente de Ernesto Geisel por indicação do presidente Médici, foi nomeado em 07 de março 1969.

- Ernani Ayres Sátyro e Souza - nomeado em 25 de abril de 1969;

- General de Exército Álvaro Alves da Silva Braga - realizou cursos na ESG. Em 1964 participa do golpe, ao lado de Ernesto e Orlando Geisel sem comando sobre tropas. Foi nomeado ministro em 30 de maio de1969;

- Waldemar Torres da Costa - nomeado em 18 de junho de 1969;

- General-de- Exército Jurandyr de Bizarria Mamede - um dos organizadores da Escola Superior de Guerra, foi general chefe da Escola do Estado Maior, da Escola Superior de Guerra e Escola Técnica do Exército, considerado um moderado da "Sorbonne Militar", os oficiais sob seu comando tomaram posição junto ao levante de Juiz de Fora em 1964. Foi nomeado em 11 de setembro de 1969, mas assume efetivamente em 1970. 